\title{
BK Virus-Plasmid Expression Vector That Persists Episomally in Human Cells and Shuttles into Escherichia coli
}

\author{
GABRIELE MILANESI, ${ }^{1}$ GIUSEPPE BARBANTI-BRODANO, 2 MASSIMO NEGRINI, ${ }^{1}$ DOUGLAS LEE,${ }^{3+}$ \\ ALFREDO CORALLINI, ${ }^{2}$ ANTONELLA CAPUTO, ${ }^{2}$ MARIA P. GROSSI, ${ }^{2}$ AND ROBERT P. RICCIARDI ${ }^{3 *}$ \\ Institute of Biochemical Genetics, National Research Council, I-27100 Pavia, ${ }^{1}$ and Institute of Microbiology, School of \\ Medicine, University of Ferrara, I-44100 Ferrara, ' Italy, and The Wistar Institute of Anatomy and Biology, Philadelphia, \\ Pennsylvania $19104^{3}$
}

Received 16 February 1984/Accepted 14 May 1984

\begin{abstract}
We describe a novel expression vector, pBK TK-1, that persists episomally in human cells that can be shuttled into bacteria. This vector includes sequences from BK virus (BKV), the thymidine kinase (TK) gene of herpes simplex virus type 1, and plasmid pML-1. TK ${ }^{+}$-transformed HeLa and 143 B cells contained predominantly full-length episomes. There were typically 20 to 40 (HeLa) and 75 to 120143 B vector copies per cell, although some 143 B transformants contained hundreds. Low-molecular-weight DNA from TK ${ }^{+}$. transformed cells introduced into Escherichia coli were recovered as plasmids that were indistinguishable from the input vector. Removal of selective pressure had no apparent effect upon the episomal status of pBK TK-1 molecules in $\mathrm{TK}^{+}$-transformed cells. BKV T antigen may play a role in episomal replication of pBK TK-1 since this viral protein was expressed in $\mathrm{TK}^{+}$transformants and since a plasmid that contained only the BKV origin of replication was highly amplified in BKV-transformed human cells that synthesize BKV $T$ antigen.
\end{abstract}

Development of eucaryotic vectors has provided a direct and convenient means of introducing additional and novel genetic information into cultured cells. Essentially, portions of all eucaryotic vectors include sequences derived from animal viruses (for extensive reviews, see references 12, 39, and 40 ). Expression systems vary widely in the way they are used. For example, infection of permissive cells occurs with particular vectors of simian virus 40 (SV40) $(13,17,34)$, adenovirus $(47,53)$, herpes simplex virus $(50)$, vaccinia virus (37), and retroviruses $(46,57)$. However, short-term or transient expression, which is noninfectious, has been described with SV40 vectors that become highly amplified in COS cells (11), e.g., 200,000 episomal copies per cell within $48 \mathrm{~h}$ of posttransfection (31). In contrast, permanent cell lines which integrate the vector DNA have been obtained in two ways by using selectable marker genes. The first has been by "per-force" selection, using the thymidine kinase (TK) gene of herpes simplex virus type 1 (HSV-1) in TKdeficient mutant cells $(44,58)$. The second has been by dominant selection in which expression of a dominant marker gene (e.g., Escherichia coli xanthine-guanine phosphoribosyltransferase) is extended to nonmutated cells $(33,55)$. In addition, permanent mouse cell lines have been obtained by transformation with bovine papillomavirus vectors which do not integrate into host cell DNA but replicate episomally and which can be shuttled into bacteria $(6,43)$.

We report here the development of a virus-plasmid expression vector, $\mathrm{pBK}$ TK-1, that has the unusual feature of being able to persist episomally in human cells. This expression vector contains DNA sequences which originate from the human papovavirus, BK virus (BKV). BKV was isolated from the urine of a renal transplant recipient on immunosuppressive therapy (9) and is ubiquitous in the human population $(2,8)$. BKV efficiently infects human cells and transforms hamster, mouse, rat, rabbit, and monkey cells in tissue culture (36). The genomic organization of the

\footnotetext{
* Corresponding author. 19104.
}

circular double-stranded DNA of BKV is remarkably similar to that of SV40, even though these viruses are infectious for different hosts. In fact, an homology of more than $80 \%$ is found in the nucleotide sequences of the two viruses $(45,59)$. As in SV40, both large $\mathrm{T}$ and small $t$ antigens of $\mathrm{BKV}$ are translated from mRNAs which initiate their transcription on one strand near the putative origin of replication (20). In parallel to SV40, capsid proteins of BKV (VP1, VP2, and VP3) are produced after DNA synthesis from late mRNAs which initiate transcription proximal to the $5^{\prime}$ end of early mRNAs on the opposite strand (20). One notable distinction between the genomes of SV40 and BKV is the extensive divergence in the DNA sequences of their tandem repeats which constitute transcriptional enhancer regions (41).

Human cells persistently infected with BKV as well as transformed human cells have been isolated $(16,35)$. In some of these viral host cell relationships, the BKV DNA resides as apparent full-length episomes, whereas in others, the BKV DNA may be free but may contain deletions or be integrated $(16,35)$. Although the mechanisms for episomal persistence of BKV DNA are not understood, we have exploited this basic feature to produce a recombinant DNA vector which will persist as an amplified episomal resident in human cells. The potential usefulness of this vector for analyzing the expression of artificially acquired genes in human cells is discussed.

\section{MATERIALS AND METHODS}

Plasmids, virus, and recombinant DNA constructions. Plasmid pML-1 (referred to here as pML) is a deletion derivative of pBR322 (25). Plasmid pHSV106 (30) was used as the source of the HSV-1 TK gene, inserted at the BamHI site. Propagation of BKV (Gardner strain) and extraction of viral DNA were by the procedure of Meneguzzi et al. (32). Details of the construction of the viral plasmids $\mathrm{pBK}$ TK-1 and pBODE are presented in the text. The source of restriction enzymes was New England Biolaboratories and Bethesda Research Laboratories, and T4 DNA ligase was from P-L Biochemicals. DNA fragments were isolated by the method of Vogelstein and Gillespie (56). The above recombinant 
molecules were introduced by transformation and screened and propagated in $E$. coli $\mathrm{Hb} 101, \mathrm{C} 600$, and MC-1061 (10, $28)$, followed by standard isolation procedures $(21,38)$.

Cell cultures, DNA transfer, and selection of transformants. Human HeLa TK-deficient $\left(\mathrm{TK}^{-}\right)$cells and human $143 \mathrm{~B}$ $\mathrm{TK}^{-}$cells were used in these experiments. HeLa cells are derived from a human carcinoma, whereas $143 \mathrm{~B}$ cells are from a human osteosarcoma (4). $\mathrm{TK}^{-}$cells were maintained in minimal essential medium (MEM) with $8 \%$ calf serum containing $30 \mu \mathrm{g}$ of bromodeoxyuridine per $\mathrm{ml}$. Before transfection, the $\mathrm{HeLa} \mathrm{TK}^{-}$and $143 \mathrm{~B} \mathrm{TK}^{-}$cells were grown for one passage in the same medium without bromodeoxyuridine. The BKV-transformed human embryonic fibroblast cell line L603 (16) was maintained in MEM with $10 \%$ fetal bovine serum at all times. Cells at ca. $60 \%$ confluency were supplied with fresh medium $4 \mathrm{~h}$ before transfection with supercoiled plasmid DNA $(20 \mu \mathrm{g}$ for about $10^{7}$ cells, unless otherwise indicated, and in the absence of carrier DNA) by the calcium phosphate precipitation procedure of Graham and van der Eb (14) as modified by Wigler et al. (58). In some instances, cells were shocked by $20 \%$ glycerol (7) $4 \mathrm{~h}$ after transfection; otherwise, the transfection medium was replaced directly with fresh nonselective medium. To select for $\mathrm{TK}^{+} \mathrm{HeLa}$ and $\mathrm{TK}^{+} 143 \mathrm{~B}$ transformants, cells were split 1:2 after $20 \mathrm{~h}$ and maintained in MEM with $8 \%$ calf serum and HAT medium $(100 \mu \mathrm{M}$ hypoxanthine, 0.4 $\mu \mathrm{M}$ aminopterin, $16 \mu \mathrm{M}$ thymidine; 24). Resulting cell colonies were either individually cloned and expanded or pooled and grown as mass cultures.

Preparation and analysis of cellular DNA. Total cellular DNA was extracted as previously described $(3,15)$. Separation of DNA into supernatant (nonchromosomal) and pellet (chromosomal) fractions was by the procedure of Hirt (18). Extraction of DNA from both fractions was by standard methods, in which proteinase $\mathrm{K}$ (Boehringer Mannheim Biochemicals) treatment $\left(50 \mu \mathrm{g} / \mathrm{ml}\right.$, overnight at $\left.37^{\circ} \mathrm{C}\right)$ was followed by phenol extraction and ethanol precipitation. The drained pellets were dissolved in $10 \mathrm{mM}$ Tris-hydrochloride $(\mathrm{pH} 7.8)$ and treated with RNase $(25 \mu \mathrm{g} / \mathrm{ml}$ at room temperature for $1 \mathrm{~h}$ ), followed by two extractions in phenol and two in chloroform-isoamyl alcohol $(24: 1$, vol/vol $)$ and precipitation in ethanol. The pellets were finally dissolved in 15 $\mathrm{mM} \mathrm{NaCl}-1.5 \mathrm{mM}$ sodium citrate.

Cellular DNA was fractionated in agarose gels and transferred to nitrocellulose filters by the Southern procedure (48). Probe DNA was labeled by nick translation (29) with $\left[\alpha-{ }^{32} \mathrm{P}\right] \mathrm{dXTP}$ (Amersham Corp.) and DNA polymerase I (Boehringer Mannheim Biochemicals). The hybridization reactions were performed either (i) in $50 \%$ formamide with $1 \times$ Denhardt solution (5), $4 \times \operatorname{SSC}(0.6 \mathrm{M} \mathrm{NaCl}$ plus $0.06 \mathrm{M}$ sodium citrate), and $4 \%$ sodium dodecyl sulfate at $37^{\circ} \mathrm{C}$ for $36 \mathrm{~h}$, followed by a series of aqueous washes at $68^{\circ} \mathrm{C}$ with the last in $0.2 \times \mathrm{SCC}-0.2 \%$ sodium dodecyl sulfate, or (ii) according to conditions described by Chenciner et al. (3). Filters were air dried and exposed to XRP-film (usually for 2 to $24 \mathrm{~h}$ ). The amount of free vector DNA in $\mathrm{TK}^{+}$transformants was determined by reconstruction experiments, in which serial dilutions of cellular DNA were electrophoresed adjacent to known amounts of pBK TK-1 DNA, blotted, and probed with vector DNA. The copy number was calculated from densitometric analysis of the autoradiograms carried out with a Corning 750 scanner.

Transformation of bacteria with cellular DNA and analysis. $E$. coli $\mathrm{Hb} 101$ or C600 was transformed with cellular DNAs by the calcium chloride procedure (27). E. coli MC-1061 was transformed by the calcium chloride-rubidium chloride pro- cedure (23). Plasmid DNA from transformants was isolated by a rapid small-scale extraction procedure (19).

Immunoprecipitation and immunofluorescence. Labeling, immunoprecipitation, and fluorescent antibody staining of $\mathrm{BKV} \mathrm{T}$ antigen in $\mathrm{TK}^{+}$-transformed human cell lines were performed as described by Grossi et al. (16) with serum from hamsters bearing tumors induced by BKV-transformed hamster cells.

\section{RESULTS}

Vector construction. Vector pBK TK-1 includes DNA sequences originating from plasmid $\mathrm{pML}, \mathrm{BKV}$, and the TK gene of HSV-1. The location of these sequences within this vector and its construction are depicted in Fig. 1. The pBK TK-1 vector was derived by digesting both plasmid pML DNA and BKV DNA with EcoRI and BamHI (Fig. 1A). The larger of the respective EcoRI-BamHI fragments of pML DNA $(2,617$ base pairs [bp]) and BKV DNA $(5,089 \mathrm{bp})$ were ligated to produce pBK-1. A BamHI fragment of HSV-1 DNA $(3,600 \mathrm{bp})$ which contains the TK gene was introduced into the single Bam $\mathrm{HI}$ site of $\mathrm{pBK}-1$ to generate vector $\mathrm{pBK}$ TK-1 (Fig. 1A). The pBK TK-1 molecule thus includes almost the entire BKV genome (5,196 bp), except for $107 \mathrm{bp}$ eliminated by digestion of BKV DNA with BamHI and $E c o$ RI. This 107-bp fragment contained sequences from each of the late viral capsid transcripts $\mathrm{Vp} 1, \mathrm{Vp} 2$, and Vp3 (54). Since BKV DNA is infectious for human cells, deletion of these late viral sequences was intended to obviate potential recombination and release of the complete viral genome from a vector containing full-length BKV DNA.

The topographical arrangement of the transcripts and pertinent coding regions of the genes contained within $\mathrm{pBK}$ TK-1 are depicted in Fig. 1B. The essential features of pBK TK-1, in addition to encoding the ampicillin resistance gene of pML and the TK gene of HSV-1, are that it contains the entire early region sequences which encode BKV large $\mathrm{T}$ and small $t$ antigens $(45,59)$. In addition, pBK TK-1 also includes the BKV origin of replication based upon related sequence homology to SV40 and the transcriptional enhancer sequences $(45,59)$. The late genes of $\mathrm{BKV}$ in $\mathrm{pBK}$ TK-1 are not only missing 107 bp as described above but are also disrupted by ligation of pML DNA at the EcoRI site and of TK DNA at the BamHI site. Plasmid pBODE, shown in Fig. 1A, is discussed later.

pBK TK-1 vector persists episomally in human cells. Human $\mathrm{TK}^{-}$HeLa cells or $143 \mathrm{~B}$ cells were transfected with pBK TK-1 vector DNA and subjected to selection in HAT medium. Individually cloned or mass culture cell lines grown in HAT medium were then analyzed. Either total cellular DNA was extracted from $\mathrm{TK}^{+}$-transformed cells, or the DNA was separated into Hirt supernatant (HS) and Hirt pellet (HP) fractions. Essentially, HS DNA contains almost entirely free, low-molecular-weight DNA, whereas HP DNA contains high-molecular-weight DNA that is most often contaminated with free DNA.

The DNA from several $\mathrm{TK}^{+}$clones of HeLa cells was extracted and examined by Southern blot analysis (48) for the presence of pBK TK-1 molecules. Analysis of HS DNA from two HeLa clones H-303 and H-384 (Fig. 2A, lanes 1 and 2 , respectively) revealed sequences that comigrated with the supercoiled (form I), circular (form II), or linear (form III) structures of $\mathrm{pBK}$ TK-1. When this same DNA from clone H-303 was digested with SalI (Fig. 2B, lane 2), which cuts pBK TK-1 once, a single band comigrated with Sall-linearized pBK TK-1 DNA (Fig. 2B, lane 1). These results indicated that full-length $\mathrm{pBK}$ TK-1 molecules persist as free 


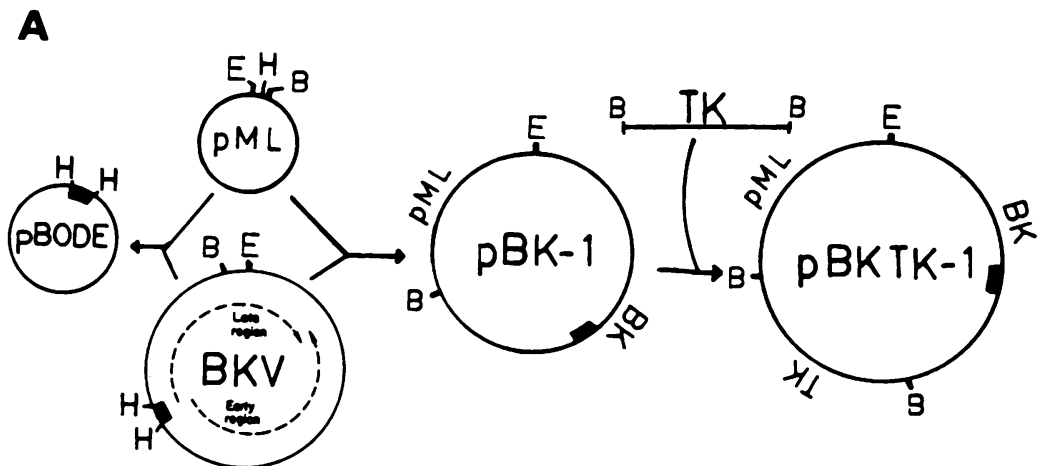

B

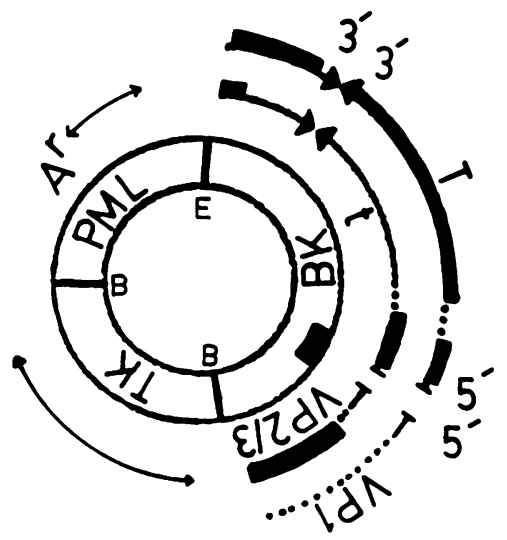

\section{PBK TK-1}

FIG. 1. Construction of vectors. (A) pBK TK-1 was constructed from BKV, the TK gene of HSV-1, and plasmid pML. pBODE was constructed from BKV and pML. The putative replication origin of BKV ( 0.67 map units) is contained in the HindIII C fragment designated by the black box. The early and late transcription regions of BKV are designated by the dotted lines. The restriction sites are EcoRI (E), BamHI (B), and HindIII (H). (B) Genomic landmarks in pBK TK-1. Locations of DNAs derived from pML, BKV, and TK (described above) in pBK TK-1 are represented in the double circle. Their respective transcripts are indicated by the thin lines, of which the dotted portion represents introns. Where pertinent, the orientation of the transcripts is shown $5^{\prime}$ to $3^{\prime}$. Coding regions (thick black lines) contained within specific BKV transcripts indicate early proteins, large $T$ and small $t$ antigens, and late capsid proteins VP1 and VP2/3. The putative BKV replication origin is represented by the black box within the circles. The bacterial ampicillin resistance gene of pML is designated by $A^{r}$. The represented restriction sites are EcoRI (E) and BamHI (B). Details are discussed in the text.

molecules in HeLa cells. To further characterize the state of vector DNA in HeLa cells, total DNA from six different $\mathrm{TK}^{+}$cloned lines was digested with $\mathrm{BamHI}$, which cuts pBK TK-1 DNA twice to generate 3,600- and 7,706-bp fragments. Five of the HeLa clones (Fig. 2C, lanes 1, 2, 3, 5, and 6) contained only two bands which comigrated with the 3,600 and 7,706-bp marker fragments (Fig. 2C, lane 7), which was expected if pBK TK-1 was episomal. Only one HeLa cell clone (Fig. 2C, lane 4) contained an additional band which may have originated from either integrated or rearranged episomal molecules of pBK TK-1 DNA; the additional bands in lane 3 represent incompletely digested free $\mathrm{pBK}$ TK-1 DNA, since they comigrated with undigested pBK TK1 DNA (lane 8). It is noted that although the autoradiogram shown in Fig. 2C had been overexposed, minor bands of pBK TK-1 which could represent integrated sequences are not detected. These results again suggested that in $\mathrm{HeLa}$ cells pBK TK-1 molecules exist as full-length episomes.

The transfected $143 \mathrm{~B} \mathrm{TK}^{+}$cell clones were also analyzed for the presence of $\mathrm{pBK}$ TK-1 molecules. Undigested HS
DNA from each of several clones (Fig. 3A, lanes 2 to 5) revealed molecules which comigrated with pBK TK-1 marker DNA (Fig. 3A, lane 1). The HS DNA from two of these cell clones, after digestion with $S a$ II which cuts pBK TK-1 once, yielded single bands (Fig. 3B, lanes 2 and 3), which comigrated with Sall-linearized pBK TK-1 DNA (Fig. 3B, lane 1). Free forms of pBK TK-1 (50 to 100 genome equivalents per diploid cell genome) were similarly observed when total cellular DNA from $143 \mathrm{~B} \mathrm{TK}^{+}$cell clones was digested with $H p a I$, a noncutter for pBK TK-1 (data not shown). Total cellular DNA from nine 143 B clones was digested with BamHI and analyzed for sequences of the expected 7,706- and 3,600-bp fragments that would be generated from nonintegrated molecules of pBK TK-1. Indeed, as seen in Fig. 3C (lanes 1 to 9), each $143 \mathrm{~B}$ clone contained both expected Bam HI fragments. However, some 143 B cell clones revealed novel bands which hybridized to the $\mathrm{pBK}$ TK-1 probe (Fig. 3C, lanes 1, 3, 4, and 8); the band below the 7,706-bp fragment of clone B4 (lane 2) is probably undigested vector DNA, since it comigrates with form I pBK TK-1 


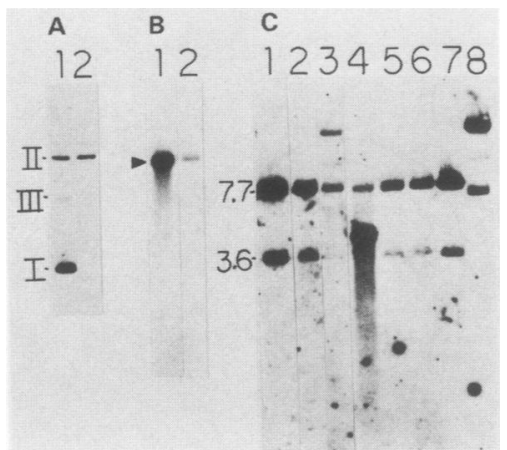

FIG. 2. Southern blots of DNA from $\mathrm{TK}^{+}$-transformed HeLa cell clones hybridized with a pBK TK-1 DNA probe. HS DNA or total cellular DNA was extracted from various individual $\mathrm{TK}^{+}$ HeLa cell clones that had been transformed by pBK TK-1. HS DNAs (corresponding to $10^{5}$ cells) and total cellular DNAs $(10 \mu \mathrm{g})$ were digested with restriction endonucleases as indicated, electrophoresed through an $0.8 \%$ agarose gel, blotted onto nitrocellulose, and probed with nick-translated pBK TK-1 DNA. (A) Undigested HS DNA from HeLa cell clones H-303 (lane 1) and H-384 (lane 2). The positions of forms I, II, and III of pBK TK-1 marker DNA are indicated. (B) HS DNA of HeLa clone H-303 digested with SalI (lane 2), and SalI-digested pBK TK-1 DNA (4.8 ng) as marker (lane 1). (C) Total cellular DNA was digested with BamHI. Lanes 1 to 6: HeLa clones H-311; H-303; H-383; H-301; H-385; H-386, respectively. pBK TK-1 DNA marker (50 genome equivalents): digested with BamHI (lane 7) and undigested (lane 8).

DNA (lane 10). These novel sequences likely represent polymeric and deleted episomal forms of $\mathrm{pBK}$ TK-1 or possibly integrated forms of the vector.

We examined whether the property of pBK TK-1 molecules to persist as episomes in individual cell clones would also extend to a mass culture prepared by pooling hundreds of individual $\mathrm{TK}^{+}$cell colonies. The DNA extracted from such a mass culture of $143 \mathrm{~B}$ cells was separated into HS and HP fractions, which, respectively, were digested with five restriction endonucleases that cut $\mathrm{pBK}$ TK-1 DNA twice (BamHI, XbaI, and KpnI) or three times (EcoRI and BglII) (Fig. 4A). As seen in Fig. 4B, in all instances, sequences of pBK TK-1 found in both the HS (lanes 1, 4, 7, 10, and 13) and HP (lanes 2, 5, 8, 11, and 14) fractions after digestion by these enzymes were those which comigrated with the corresponding digestions of marker pBK TK-1 DNA (lanes 3, 6, 9, 12 , and 15). The observation that most of the hybridized sequences from each HP fraction comigrated with the respective restriction fragments of marker pBK TK-1 DNA indicated that most of these molecules originated from $\mathrm{pBK}$ TK-1 episomes and that only negligible amounts, if any, of this vector DNA integate into chromosomal DNA. Additional bands, particularly in the HS fraction, could represent incompletely digested pBK TK-1 DNA molecules, free molecules containing deletions, or degraded forms of $\mathrm{pBK}$ TK-1 DNA. Since these results were obtained with a mass culture, they are representative of hundreds of individually transfected cells. This finding demonstrates clearly that in the majority of independently transfected human cells pBK TK-1 molecules persist in the free state.

The average number of free $\mathrm{pBK}$ TK-1 copies maintained per cell was between 75 and 120 in 143 B cells and 20 and 40 in HeLa cells. It is important to note that in some $143 \mathrm{~B}$ clones (e.g., clones B-23 and B-36; Fig. 3C, lanes 7 and 9), many times this number of copies persisted.

pBK TK-1 DNA can be shuttled from human cells into $E$. coli. To further substantiate that pBK TK-1 DNA molecules persist as stable replicating episomes in human cells, HS DNAs from both HeLa and $143 \mathrm{~B}$ cell clones were used to transform $E$. coli to an ampicillin-resistant phenotype. In one experiment, half of a sample of the HS DNA from two clones of HeLa cells and six clones of 143 B cells was directly used to transform $E$. coli $\mathrm{MC}-1061$, whereas the other half was treated with the restriction endonuclease $\mathrm{MboI}$ (which has 17 restriction sites within pBK TK-1 DNA) before transformation. DNA is not cut when the adenine within the recognition sequence of $\mathrm{MboI}$ (GATC) is methylated, as occurs in most $E$. coli strains including Hb101 and MC-1061.

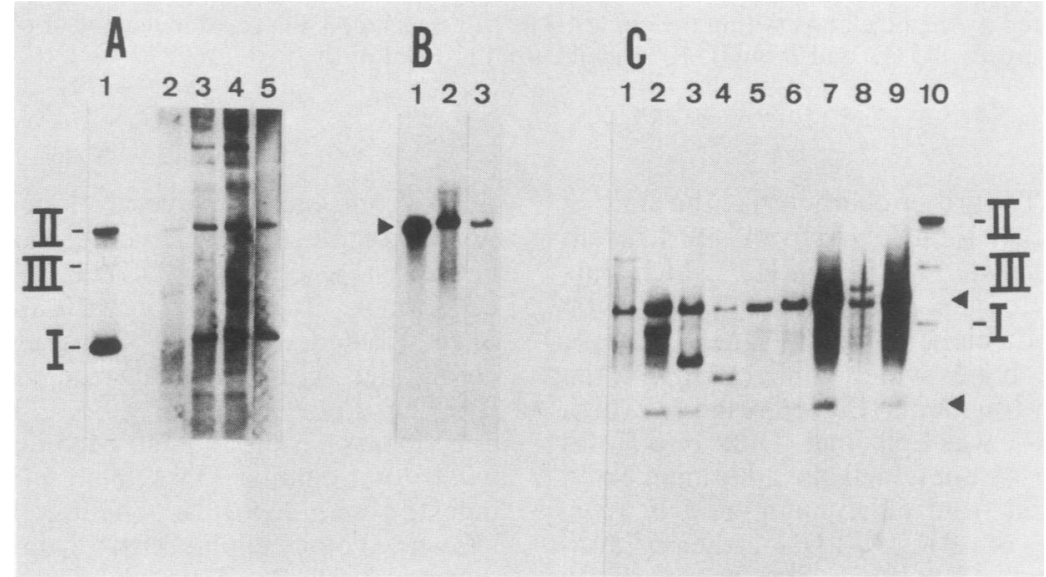

FIG. 3. Southern blots of DNA from $\mathrm{TK}^{+}$-transformed 143 B cell clones hybridized with pBK TK-1 DNA. HS DNA or total cellular DNA was extracted from various individual $\mathrm{TK}^{+} 143 \mathrm{~B}$ cell clones that had been transformed by $\mathrm{pBK}$ TK-1 DNA. HS DNAs (corresponding to $10^{5}$ cells) and total cellular DNAs $(10 \mu \mathrm{g})$ were digested with the indicated restriction endonucleases, electrophoresed through a $0.6 \%$ agarose gel, blotted onto nitrocellulose, and probed with nick-translated pBK TK-1 DNA. (A) HS DNA from 143 B clones B-6, B-27, B-31, and B-20 (lanes 2 to 5, respectively); lane 1, 4.8 ng of pBK TK-1 DNA marker. (B) Sall digestion of HS DNA of 143 B clones B-31 (lane 2) and B-27 (lane 3); lane 1, $4.8 \mathrm{ng}$ of Sall-digested pBK TK-1 marker DNA (arrow). (C) Total cellular DNA from 143 B clones digested with BamHI; lanes 1 to 9 , 143 B clones B-1, B-4, B-6, B-8, B-18, B-20, B-23, B-31, and B-36, respectively; lane 10, undigested pBK TK-1 DNA marker (100 genome equivalents). The upper and lower arrows indicate the positions of the 7,706 and 3,600-bp fragments, respectively, generated by $B a m \mathrm{HI}$ digestion of pBK TK-1 DNA. 
A

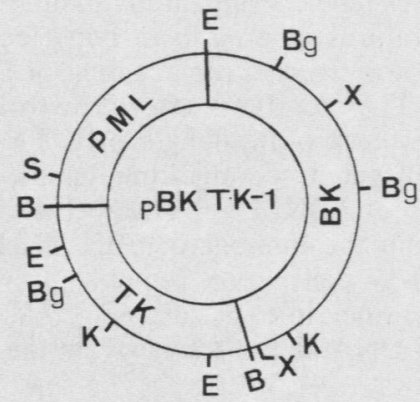

B

\begin{tabular}{|c|c|c|c|c|}
\hline Bam HI & Xba I & Eco RI & $\mathrm{Bgl} \mathrm{I}$ & Kpn I \\
\hline
\end{tabular}

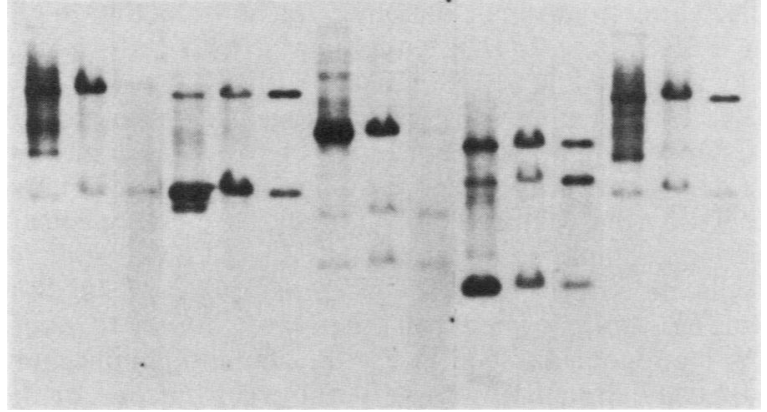

FIG. 4. (A) Positions of BamHI (B), BglII (Bg), EcoRI (E), KpnI $(\mathrm{K})$, and $\mathrm{Xbal}(\mathrm{X})$ restriction sites in $\mathrm{pBK}$ TK-1. The unique $S a l \mathrm{I}(\mathrm{S})$ site is suitable for insertion of additional genes. (B) Southern blot of DNA from $\mathrm{TK}^{+}$-transformed $143 \mathrm{~B}$ mass culture cells hybridized to pBK TK-1 DNA. HS and HP DNAs were extracted from TK ${ }^{+} 143$ B mass culture cells, digested with restriction endonucleases $B a m \mathrm{HI}$, $X b a I, E c o$ RI, Bg/II, and KpnI, electrophoresed through a $1.0 \%$ agarose gel, blotted onto nitrocellulose, and probed with nicktranslated pBK TK-1 DNA. Lanes $1,4,7,10$, and 13 show HS DNA from $10^{5}$ cells; lanes $2,5,8,11$, and 14 show HP DNA ( $\left.10 \mu \mathrm{g}\right)$; lanes $3,6,9,12$, and 15 show pBK TK-1 marker DNA (1 ng or 50 genome equivalents).

However, the DNA becomes sensitive to MboI digestion after replication in eucaryotic cells, where the adenine is not methylated. The untreated HS DNA from each HeLa and 143 B cell clone did transform $E$. coli MC-1061, whereas digestion by $\mathrm{MboI}$ rendered these same DNAs incapable of transformation (Table 1). The transforming ability of pBK TK-1 DNA directly isolated from $E$. coli Hb101 was unaffected by $M b o I$ treatment. These results indicate that pBK TK-1 does replicate as a free molecule in human cells and that the gene for ampicillin resistance remains functional.

Replication of pBK TK-1 in $\mathrm{TK}^{+}$transformants was further supported by blot hybridization analysis. The HS DNA from each of seven $143 \mathrm{~B} \mathrm{TK}^{+}$individual clones was completely digested by $\mathrm{MboI}$ (lanes 3 to 9), whereas the control pBK TK-1 was not (lanes 1 and 2) (Fig. 5).

In another experiment, plasmids recovered from $E$. coli MC-1061 transformed by HS DNAs from either HeLa or 143 $\mathrm{B} \mathrm{TK}^{+}$cells were compared to input DNA. The plasmids from ampicillin-resistant colonies were digested with EcoRI,
TABLE 1. Transformation of $E$. coli MC-1061 with HS DNAs from $\mathrm{HeLa}$ and $143 \mathrm{~B}$ cell clones transformed to the $\mathrm{TK}^{+}$ phenotype by pBK TK-1

\begin{tabular}{|c|c|c|}
\hline \multirow{2}{*}{ Cell clones } & \multicolumn{2}{|c|}{$\begin{array}{l}\text { No. of Amp } \text { Aacterial }^{\text {colonies }}{ }^{a}\end{array}$} \\
\hline & Untreated & $\begin{array}{c}\text { Treated with } \\
\text { MboI }\end{array}$ \\
\hline HeLa H-303 & 28 & ND \\
\hline HeLa H-384 & 114 & ND \\
\hline 143 В 656 & 95 & 0 \\
\hline 143 В 657 & 233 & 0 \\
\hline 143 B F6-D4 & 30 & 0 \\
\hline 143 В 633 & 28 & 0 \\
\hline 143 В B-27 & 25 & 0 \\
\hline 143 В B-3 & 150 & 0 \\
\hline pBK TK-1 DNA (control, $10 \mathrm{ng}$ ) & 26,400 & 21,000 \\
\hline
\end{tabular}

${ }^{a}$ Amp $^{r}$ bacterial colonies were produced by transformation of $E$. coli with samples of HSs obtained from $10^{5}$ cells. ND, Not done.

which cuts pBK TK-1 three times (Fig. 4A), and the fragments thus obtained were analyzed in agarose gels. As seen in Fig. 6A (lanes 1 to 12), plasmid DNA from each of 12 ampicillin-resistant colonies transformed by the HS DNA of HeLa cell line H-303 contained three EcoRI restriction fragments that comigrated with those of pBK TK-1 DNA (lane 15). No other DNA bands were seen; the highermolecular-weight bands seen in lanes 6 and 12 (Fig. 6A) probably represent incomplete digestions. A similar analysis with the $\mathrm{HS}$ of an individual $143 \mathrm{~B}$ cell clone revealed that the plasmid DNAs from 11 of 12 bacterial transformants were indistinguishable from that of the input vector (data not shown). In addition, the HS DNA from a mass culture of 143 B cells was also used to transform $E$. coli $C 600$. Plasmids extracted from 18 ampicillin-resistant colonies were ana-

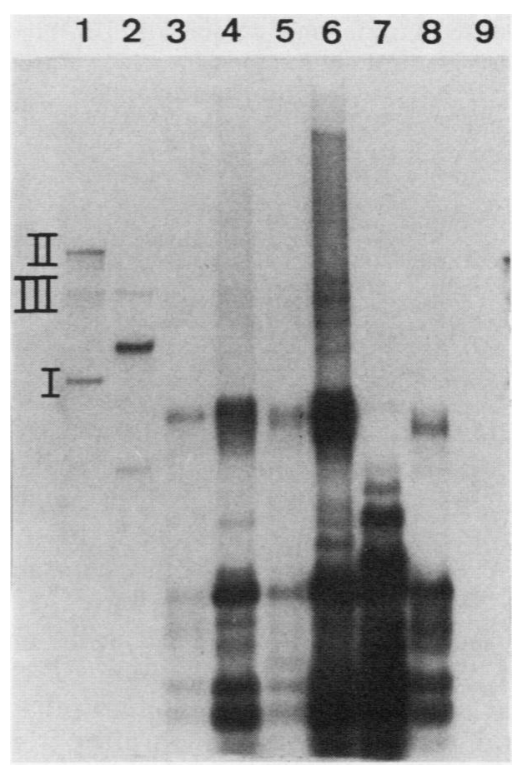

FIG. 5. Digestion with $\mathrm{MboI}$ and blot hybridization analysis of 143 B cell clones transformed to the $\mathrm{TK}^{+}$phenotype by pBK TK-1. HS DNA from $10^{5}$ cells was restricted with $\mathrm{MboI}$, migrated in a $1 \%$ agarose gel, transferred to nitrocellulose, and hybridized to a pBK TK-1 probe. Lanes 3 to 9, 143 B clones B-18, B-28, B-6, B-23, B-36, B-31, and B-2, respectively; lane 1, pBK TK-1 marker digested with MboI (2.4 ng); lane 2, pBK TK-1 digested with BamHI and $\mathrm{MboI}$ (2.4 ng). Forms I, II, and III of marker PBK TK-1 are indicated. 


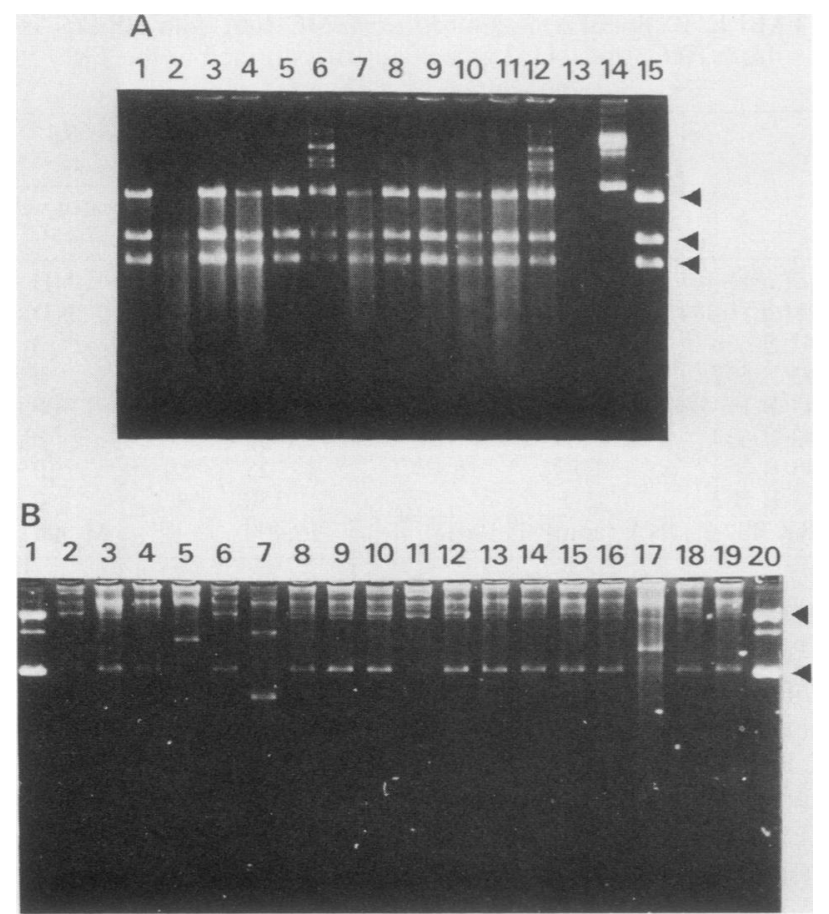

FIG. 6. pBK TK-1 from $\mathrm{TK}^{+}$-transformed HeLa and 143 B cells is shuttled into $E$. coli and reestablished as plasmids. HS DNA from $\mathrm{TK}^{+} \mathrm{HeLa}$ and $143 \mathrm{~B}$ cells that had been transformed by $\mathrm{pBK}$ TK-1 was used to transform E. coli MC-1061 (A) or C600 (B). Plasmid DNAs were prepared from $E$. coli ampicillin-resistant $\left(\mathrm{Amp}^{\mathrm{r}}\right)$ colonies, electrophoresed in $1 \%$ agarose gels, and visualized by ethidium bromide staining at $280 \mathrm{~nm}$. (A) $E c o$ RI digestion of plasmids from Amp ${ }^{r}$ colonies, transformed by HS DNA of HeLa cell clone H-303 (lanes 1 to 12). Marker pBK TK-1 was uncut (lane 14) or digested with EcoRI (lane 15). The arrows point to the three fragments generated by EcoRI digestion (Fig. 4A). Lane 13 is blank. (B) Plasmids (undigested) from $\mathrm{Amp}^{\mathrm{r}}$ colonies transformed by HS DNA from 143 B mass culture cells (lanes 2 to 19). Marker pBK TK-1 DNA is in lanes 1 and 20. The lower arrow indicates the position of supercoiled (form I) pBK TK-1 plasmid DNA, and the upper arrow marks its relaxed circular form (form II).

lyzed directly in agarose gels. As seen in Fig. 6B, 15 of 18 colonies (lanes 2 to 19) contained supercoiled and relaxed circular molecules that comigrated with form I and form II DNA of pBK TK-1 (lanes 1 and 20). Two plasmids contained an insertion (Fig. 6B, lanes 5 and 17) and a third plasmid contained a deletion (lane 7), as confirmed by restrictionenzyme analysis (data not shown). These results show that in human cell lines originating either from a single transfected cell or from a mixture of hundreds of independently transfected cells, pBK TK-1 DNA persists as stable fulllength episomes for many cell generations.

pBK TK-1 vector continues to persist in the episomal state after removal of selective growth medium. In all the experiments thus far described, the $\mathrm{TK}^{-}$human cells were placed under conditions of selective growth after transfection by pBK TK-1 DNA. Since only $\mathrm{TK}^{+}$cells are able to survive in HAT medium, it was not apparent whether selective pressure was required for maintenance of stable episomes. Therefore, an individual clone of 143 B cells (B-27) and a mass culture of $143 \mathrm{~B}$ cells which contained pBK TK-1 DNA were removed from the selective HAT medium and placed onto nonselective Eagle MEM.

Surprisingly, pBK TK-1 DNA molecules from the HS of clone B-27 cells maintained in HAT medium for 200 generations (Fig. 7A, lane 2) appeared qualitatively unchanged after 25 generations of growth in nonselective MEM (Fig. 7A, lane 3). Furthermore, replacement of HAT medium for an additional 25 generations after growth in MEM did not alter the persistence of full-length pBK TK-1 episomes; the high-molecular-weight comigrating bands probably represent polymers of pBK TK-1 DNA (Fig. 7A, lane 4). No apparent loss in the number of pBK TK-1 molecules was detected in B-27 cells upon removal or reintroduction of HAT medium, since in each case (Fig. 7A, lanes 2 to 4 ) the amount of HS DNA analyzed was from the same number of cells.

A similar analysis of the $143 \mathrm{~B}$ mass culture also proved that maintenance of stable pBK TK-1 episomal DNA in these cells is not dependent upon selection in HAT medium. In this experiment, $143 \mathrm{~B}$ mass culture cells that had been maintained in HAT medium for 5 months were switched to growth in nonselective MEM for 3 months (48 generations). As seen in Fig. 7B, the Southern blot of HS and HP fractions digested with BamHI reveals no obvious change in pBK TK1 DNA after many cell doublings in nonselective medium (lane 1, HS; lane 2, HP) as compared with cells grown in HAT medium (lane 3, HS; lane 4, HP).

pBK TK-1 synthesizes BKV $T$ antigen. It is possible that persistence of amplified episomes of pBK TK-1 in human cells may depend upon expression of BKV large $\mathrm{T}$ antigen encoded by the vector. This hypothesis seemed reasonable, since large T antigen of the closely related SV40 stimulates its replication (for review, see reference 54). Both 143 B- and $\mathrm{HeLa} \mathrm{TK}{ }^{+}$-transformed cell lines were found to express BKV T antigen. As seen in Fig. 8, immunoprecipitation of the 95,000-dalton BKV large $\mathrm{T}$ antigen from one of these lines occurs with a specific hamster serum to BKV T antigen

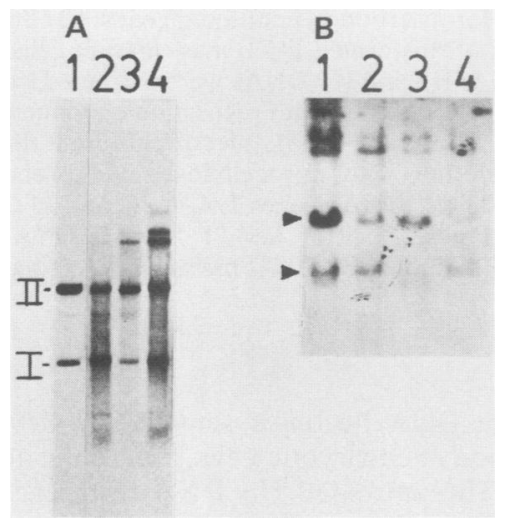

FIG. 7. Blot hybridization of HS DNA from $\mathrm{TK}^{+}$-transformed 143 B cells maintained with and without selective HAT medium. Undigested or BamHI-restricted DNA was electrophoresed through a $0.6 \%$ agarose gel (A) or a $1 \%$ agarose gel (B), blotted onto nitrocellulose, and probed with nick-translated pBK TK-1 DNA. (A) HS DNA (undigested and corresponding to $10^{5}$ cells) from $143 \mathrm{~B}$ cell clone B-27, maintained first in HAT medium for more than 200 generations (lane 2), then for 25 generations in nonselective MEM (lane 3), and then replaced into HAT medium for 25 generations (lane 4). pBK TK-1 marker DNA (2.4 ng), indicating forms I and II, is shown in lane 1. (B) BamHI-digested DNA from 143 B mass culture cells that had been maintained for 5 months in HAT medium HS DNA (lane 3) and HP DNA (lane 4). DNA from the same cells after 3 months in nonselective MEM: HS DNA (lane 1) and HP DNA (lane 2). Uppermost bands represent partial DNA digests. Positions of the two fragments generated by BamHI digestion of pBK TK-1 are shown by the arrows. 


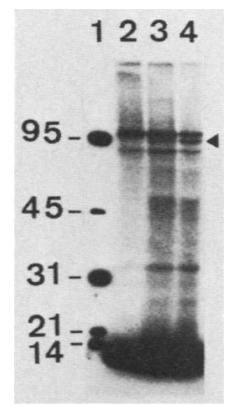

FIG. 8. Immunoprecipitation of BKV T antigen from $143 \mathrm{~B}$ cells transformed by $\mathrm{pBK}$ TK-1. $\mathrm{TK}^{+} 143 \mathrm{~B}$ cells (clone B-633) were labeled with ${ }^{32} \mathrm{P}_{\mathrm{i}}$, and anti-T hamster serum was used to immunoprecipitate BKV T antigen as described in the text. The immunoprecipitated products were fractioned in a $10 \%$ polyacrylamide gel. Labeled cell extracts were reacted with normal hamster serum (lane 2), $15 \mu \mathrm{l}$ of anti-T serum (lane 3), or $30 \mu \mathrm{l}$ of anti-T serum (lane 4). Protein molecular weight standards in kilodaltons are in lane 1: phosphorylase $b, 95$; ovalbumin, 45 ; carbonic anhydrase, 31 ; trypsin inhibitor, 21; lysozyme, 14. The arrow indicates the position of the 95,000 molecular-weight BKV large T antigen.

(lanes 3 and 4), but not with a normal serum (lane 2). In addition, BKV T antigen was also detected by immunofluorescence in $143 \mathrm{~B}$ cells stably transformed to the $\mathrm{TK}^{+}$ phenotype by pBK TK-1 (Fig. 9).

pBK TK-1 contains an active origin of replication. As a corollary to these findings, it was important to demonstrate directly that $\mathrm{pBK}$ TK-1 DNA contains viral sequences responsible for replication in the presence of $\mathrm{BKV} T$ antigen. The BKV origin of replication, in fact, is predicted to be located at 0.67 map units, based upon extensive sequence homology to the known origin of replication in SV40 $(45,59)$. Therefore, the HindIII C fragment (555 bp) of BKV which contains sequences including the origin of replication was cloned into pML (Fig. 1A). The resulting recombinant, referred to as pBODE (Fig. 1A), was transfected into L603 cells. These cells are human embryonic fibroblasts that had been transformed by a BKV DNA fragment containing the entire early region and are $100 \%$ positive for BKV $\mathrm{T}$ antigen (16). The intent was to see whether the pBODE molecule, containing the predicted BKV origin of replication but void of any complete viral genes, would be amplified in cells that constitutively produce BKV T antigen. The HS DNA was extracted at 16,50 , and $81 \mathrm{~h}$ posttransfection, linearized with BamHI, and analyzed by Southern blotting, using pBODE as the labeled probe. The pBODE molecule is greatly amplified, since densitometric analysis of the autoradiograms showed that the amount of pBODE DNA increases from $0.04 \mathrm{ng}$ at $16 \mathrm{~h}$ posttransfection (Fig. 10, lane 1) to $29 \mathrm{ng}$ at 50 $\mathrm{h}$ (lane 2) and then decreases to $3.7 \mathrm{ng}$ at $81 \mathrm{~h}$ (lane 3). Therefore, reduction in copy number at $81 \mathrm{~h}$ posttransfection defines this amplification as transient. The pBODE molecules were not amplified in 143 B cells (data not shown). These results indicate that the 0.67-map-unit region of $\mathrm{BKV}$ present in the pBK TK-1 molecule serves as an active replication origin which is stimulated by BKV T antigen.

\section{DISCUSSION}

We describe an expression vector, pBK TK-1, which is able to persist episomally in human cells. This vector includes sequences derived from BKV, a human papovavirus; pML, a deletion derivative of plasmid pBR322 (25); and the TK gene of HSV-1, which transforms $\mathrm{TK}^{-}$mutant cells to the $\mathrm{TK}^{+}$phenotype (58). Free molecules of pBK TK-1 were detected in the low-molecular-weight DNA fraction of established $\mathrm{TK}^{+}$-transformed cells. Enzymatic expression of the TK gene of HSV-1 was also detected in the $\mathrm{TK}^{+}$ transformants (unpublished data). The origin of the human cell into which pBK TK-1 was introduced influenced to a certain extent its episomal status both quantitatively and qualitatively. In HeLa and $143 \mathrm{~B} \mathrm{TK}^{+}$cell transformants, the numbers of extrachromosomal copies of $\mathrm{pBK}$ TK-1 per
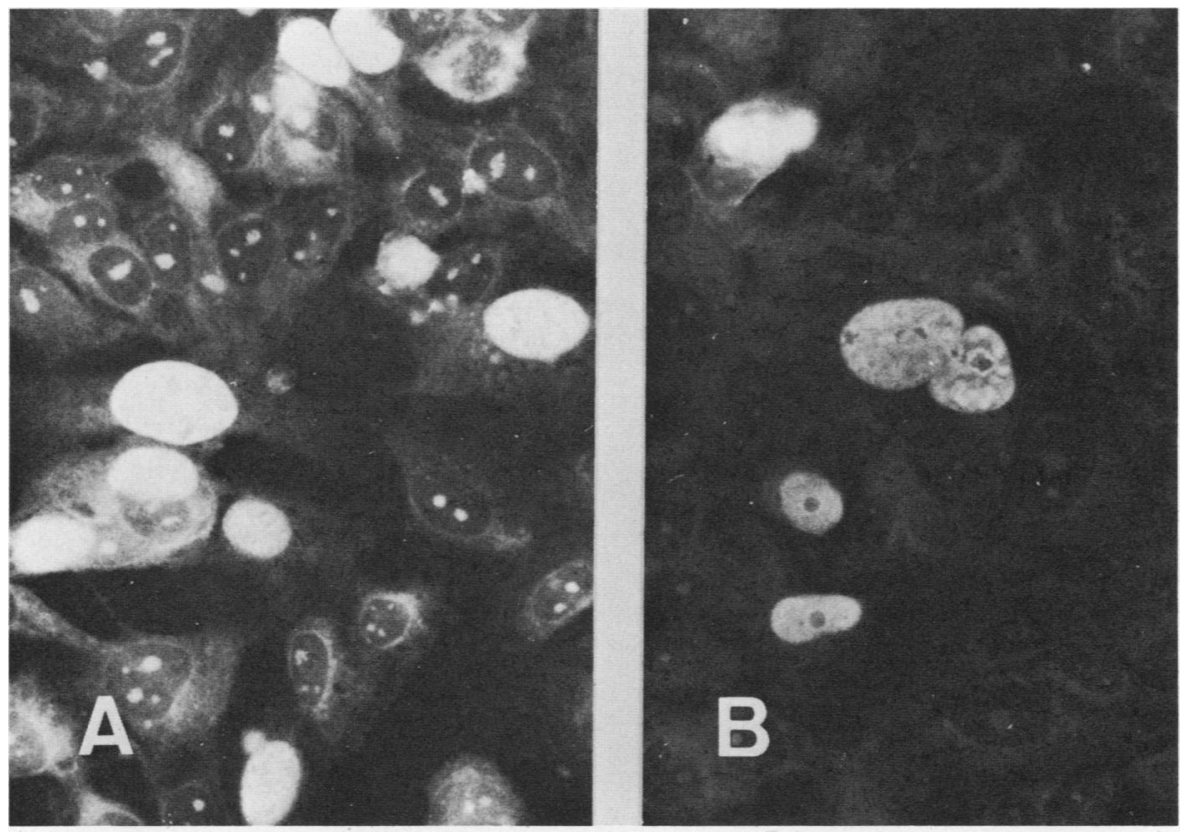

FIG. 9. Fluorescent antibody staining for BKV T antigen in $143 \mathrm{~B} \mathrm{TK}^{+}$cells transformed by pBK TK-1. Cells were first reacted with a specific hamster serum to BKV T antigen and then with fluorescein-conjugated goat antibodies to hamster immunoglobulin G. (A) Clone B-28 and $(\mathrm{B})$ clone B-31. 


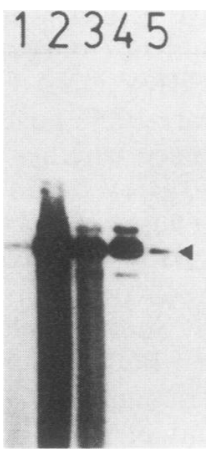

FIG. 10. Amplification of $\mathrm{pBODE}$, a BKV origin recombinant plasmid, in BKV-transformed human cells positive for BKV $T$ antigen, as analyzed by Southern blot hybridization. The BKVtransformed human cells, L603, in which the BKV T-antigen gene is integrated and expressed, were transfected with pBODE $(10 \mu \mathrm{g}$ of DNA per $10^{7}$ cells). At indicated times after transfection, cells were rigorously washed, and HS DNA was prepared. Samples of HS DNA corresponding to $10^{5}$ cells were digested with $B a m \mathrm{HI}$, electrophoresed through a $0.6 \%$ agarose gel, blotted onto nitrocellulose, and probed with nick-translated pBODE DNA. Lane $1,16 \mathrm{~h}$ posttransfection; lane $2,50 \mathrm{~h}$ posttransfection; lane $3,81 \mathrm{~h}$ posttransfection. Marker pBODE DNA cut with BamHI is shown in lane $4(3.5 \mathrm{ng})$ and lane $5(0.07 \mathrm{ng})$. The arrow points to linear form III of pBODE DNA.

cell were generally 20 to 40 and 75 to 120 , respectively. In HeLa cells, pBK TK-1 molecules almost exclusively appeared as full-length episomes with undetectable rearrangements. Although all $143 \mathrm{~B}$ transformants contained fulllength episomes, additional free forms that probably included polymeric and deleted molecules were observed in some clones. The nature of these rearranged molecules is unknown. In this connection, it must be pointed out that in BKV-transformed human cells, where BKV DNA replicates episomally, free unintegrated polymeric forms of the viral genome were constantly detected in considerable amounts (16). In all cases, however, full-length pBK TK-1 molecules were the predominant episomal form as specifically demonstrated in $143 \mathrm{~B}$ mass culture cells, which represented a pool of hundrds of individual $\mathrm{TK}^{+}$colonies. In both $\mathrm{HeLa}$ and $143 \mathrm{~B}$ cells, integration of $\mathrm{pBK}$ TK-1 into chromosomal DNA appeared infrequent and certainly negligible in proportion to the number of amplified free molecules.

The pBK TK-1 molecules from $\mathrm{TK}^{+}$-transformed human cells can be readily shuttled into bacteria. Surprisingly, almost $85 \%$ of the Amp ${ }^{r}$ bacterial colonies transformed by DNA from the $143 \mathrm{~B} \mathrm{TK}^{+}$mass culture cells contained plasmid DNA that was indistinguishable from the input $\mathrm{pBK}$ TK-1 vector DNA; this value was near $100 \%$ when DNA from a $\mathrm{TK}^{+} \mathrm{HeLa}$ or $143 \mathrm{~B}$ cell clone was used. Furthermore, plasmid DNA could not be rescued in bacteria when these cellular DNAs were digested with the endonuclease $M b o I$, which selectively restricts DNA that has replicated in animal cells. Not only do these results demonstrate definitively that $\mathrm{pBK}$ TK-1 persists as stable replicons in human cells, but they also show that a resident bacterial gene, which confers no selective advantage to the eucaryotic cell, retains its capacity to function, i.e., the $\beta$-lactamase gene of pML which confers ampicillin resistance in $E$. coli.

Importantly, episomal maintenance of pBK TK-1 in human cells does not appear to depend upon forced expression of the TK gene under selection for the $\mathrm{TK}^{+}$phenotype, since the vector is not drastically affected by removal of HAT medium. This is in contrast to a report which describes the loss of TK-plasmid recombinant episomes in transformed rodent cells after removal of selective medium (51). Our experiments indicate that the sequences inherent in the BK viral moiety of pBK TK-1 dictate the copy level and stability of the vector. This further suggests that any dominant selection marker gene (33) may be substituted for the TK gene of HSV-1 to thereby extend the spectrum of human cell types into which this novel expression vector can be introduced and amplified. The possibility that an origin of replication in HSV-1 TK gene could be responsible for the episomal state of the vector, as suggested by others (51), was ruled out because only 0.2 copies of free plasmid DNA per cell were detected in HS DNA of 143 B cells transformed to the $\mathrm{TK}^{+}$ phenotype by a recombinant molecule containing only pML and the HSV-1 TK gene. In this case, essentially all vector DNA sequences were found to be integrated into highmolecular-weight DNA of the $\mathrm{TK}^{+}$transformants (G. Barbanti-Brodano, unpublished data).

The features which control the episomal replication function of pBK TK-1 are unknown. It seems unlikely that the late BK viral genes are involved in episomal maintenance of pBK TK-1 since they were partially deleted to circumvent potential infection. However, the early viral large $T$ - and small t-antigen genes are completely encoded in pBK TK-1. It is likely that the immunoreactive BKV large $\mathrm{T}$ antigen in the $\mathrm{TK}^{+}$-transformed cells stimulates the $\mathrm{BKV}$ origin of replication in pBK TK-1 analogous to SV40 T-antigendependent replication (54). The supportive argument for this mechanism is demonstrated by the great amplification of plasmid pBODE, which contains the putative BKV origin of replication ( 0.67 viral map units; $42,45,59)$, but is void of complete early and late BKV genes, in BKV-transformed human cells that constitutively synthesize BKV T antigen.

This BKV T-antigen-dependent replication of $\mathrm{pBODE}$ is similar to transient replication of SV40 vectors in COS cells (31). It is intriguing to consider that in $\mathrm{TK}^{+}$transformants the copy level of pBK TK-1 may be held constant by autoregulation of BKV T-antigen synthesis, similar to control of SV40 T-antigen production during lytic infection (1, $22,52)$. We have begun constructing deletion mutants in the T-antigen gene of pBK TK-1 to define potential elements necessary for episomal replication. Alternatively, maintenance of the episomal state of pBK TK-1 in human cells may depend on specific viral sequences, not necessarily related to the $\mathrm{T}$-antigen coding region, similar to what has been shown for vectors based on bovine papillomavirus DNA (26). A search for such sequences in the BKV genome is under way. Finally, it cannot be ruled out that replication of the vector is also under the control of some host cell components.

The pBK TK-1 molecule represents the first stable expression vector that persists episomally in human cells and that can be shuttled into bacteria. These features are also shared by the bovine papillomavirus-plasmid vectors that function in mouse cells $(6,43)$. Key advantages and potential uses of the episomal pBK TK-1 expression vector are the following. (i) The inserted gene of interest cannot be interrupted or subjected to regulatory constraints that frequently occur from integration into cellular DNA. (ii) The gene of interest is amplified with the vector. (iii) The vector can be used to study genes which are normally expressed or require expression in human cells. For example, we have produced human cell lines in which the episomal vector contains adenovirus type 12 transforming genes and expresses functional and immunoreactive adenovirus type 12 E1A proteins (R. Vasa- 
vada, G. Barbanti-Brodano, and R. P. Ricciardi, unpublished data). The pBK TK-1 vector contains restriction sites convenient for different cloning strategies. (v) Substitution of the TK gene with a dominant selection gene such as Tn5 aminoglycoside phosphotransferase (49) or $E$. coli xanthineguanine phosphoribosyltransferase (33) in the vector predictably will expand the variety of human cells that can be used. (vi) The system may be applied in transient assays as suggested from this study with pBODE in L603 cells. Indeed, we have already prepared a pBODE-CAT (chloramphenicol acetyltransferase) recombinant that transiently expresses high enzyme activity in $143 \mathrm{~B} \mathrm{TK}^{+}$transformants containing pBK TK-1 (A. Caputo, G. Barbanti-Brodano, and R. P. Ricciardi, unpublished data). (vii) The pBK TK-1 recombinant may be modified for the insertion and expression of cDNAs.

\section{ACKNOWLEDGMENTS}

We are grateful to and acknowledge support of Carlo M. Croce (The Wistar Institute) in assisting in this project.

This work was supported by Public Health Service grant CA29797 from the National Cancer Institute and a Ruth Estrin Goldberg Memorial for Cancer Research grant to R.P.R. This work was also supported by Consiglio Nazionale delle Ricerche-Progetto Finalizzato "Ingegneria Genetica e Basi Molecolari delle Malattie Ereditarie" and by North Atlantic Treaty Organization research grant 284.81 .

\section{LITERATURE CITED}

1. Alwine, J. C., S. I. Reed, and G. R. Stark. 1977. Characterization of the autoregulation of simian virus 40 gene $A$. J. Virol. 24:22-27.

2. Brown, P., T. Tsai, and D. C. Gajdusek. 1975. Seroepidemiology of human papovaviruses: discovery of virgin populations and some unusual patterns of antibody prevalence among remote peoples of the world. Am. J. Epidemiol. 102:331-340.

3. Chenciner, N., M. P. Grossi, G. Meneguzzi, A. Corallini, R. Manservigi, G. Barbanti-Brodano, and G. Milanesi. 1980. State of viral DNA in BK virus-transformed rabbit cells. Virology 103:138-148.

4. Croce, C. M., J. Barrick, A. Linnenbach, and H. Koprowski. 1979. Expression of malignancy in hybrids between normal and malignant cells. J. Cell Physiol. 99:279-286.

5. Denhart, D. T. 1966. A membrane-filter technique for the detection of complementary DNA. Biochem. Biophys. Res. Commun. 23:641-646.

6. Dimaio, D., R. Treisman, and T. Maniatis. 1982. Bovine papilloma-virus that propagates as a plasmid in both mouse and bacterial cells. Proc. Natl. Acad. Sci. U.S.A. 79:4030-4034.

7. Frost, E., and J. Williams. 1978. Mapping temperature-sensitive and host-range mutations of adenovirus type 5 by marker rescue. Virology 91:39-50.

8. Gardner, S. D. 1973. Prevalence in England of antibodies to human polyomavirus (BK). Br. Med. J. 1:77-78.

9. Gardner, S. D., A. M. Field, D. V. Coleman, and B. Hulme. 1971. New human papovavirus (BK) isolated from urine after renal transplantation. Lancet $\mathrm{i}: 1253-1257$.

10. Gergen, J. P., R. H. Stern, and P. C. Wensink. 1979. Filter replicas and permanent collections of recombinant DNA plasmids. Nucleic Acids Res. 7:2115-2136.

11. Gluzman, Y. 1981. SV40-transformed simian cells support the replication of early SV40 mutants. Cell 23:175-182.

12. Gluzman, Y. 1982. Eukaryotic viral vectors. Cold Spring Harbor Laboratory, Cold Spring Harbor, N.Y.

13. Goff, S. P., and P. Berg. 1976. Construction of hybrid viruses containing SV40 and $\lambda$ phage DNA segments and their propagation in cultured monkey cells. Cell 9:965-705.

14. Graham, F. L., and A. J. van der Eb. 1973. A new technique for the assay of infectivity of human adenovirus 5 DNA. Virology 52:456-467.

15. Gross-Bellard, M., P. Oudet, and P. Chambon. 1973. Isolation of high molecular weight DNA from mammalian cells. Eur. J. Biochem. 36:32-38.

16. Grossi, M. P., A. Caputo, G. Meneguzzi, A. Corallini, L. Carra, M. Portolani, M. Borgatti, G. Milanesi, and G. Barbanti-Brodano. 1982. Transformation of human embryonic fibroblasts by BK virus, BK virus DNA and a subgenomic BK virus DNA fragment. J. Gen. Virol. 63:393-403.

17. Hamer, D. H., D. Davoli, C. A. Thomas, and G. C. Fareed. 1977. Simian virus 40 carrying an Escherichia coli suppressor gene. J. Mol. Biol. 112:155-182.

18. Hirt, B. 1967. Selective extraction of polyoma DNA from infected mouse cell cultures. J. Mol. Biol. 26:365-369.

19. Holmes, D. S., and M. Quigley. 1981. A rapid method for the preparation of bacterial plasmids. Anal. Biochem. 114:193-197.

20. Howley, P. M. 1980 . Molecular biology of SV40 and the human polyomaviruses BK and JC, p. 489-550. In G. Klein (ed.), Viral oncology. Raven Press, New York.

21. Katz, L., D. T. Kingsbury, and D. R. Helinski. 1973. Stimulation by cyclic adenosine monophosphate of plasmid deoxyribonucleic acid replication and catabolite repression of the plasmid deoxyribonucleic acid-protein relaxation complex. J. Bacteriol. 114:577-591.

22. Khoury, G., and E. May. 1977. Regulation of early and late simian virus 40 transcription: overproduction of early viral RNA in the absence of a functional T-antigen. J. Virol. 23:167-176.

23. Kushner, S. R. 1978. An improved method for transformation of Escherichia coli with Col E1-derived plasmids, p. 17. In $\mathrm{H}$. Boyer and S. Nicosia (ed.), Genetic engineering. Elsevier/ North-Holland, Amsterdam.

24. Littlefield, J. W. 1965. The use of drug-resistant markers to study the hybridization of mouse fibroblasts. Exp. Cell Res. 41:190-196.

25. Lusky, M., and M. Botchan. 1981. Inhibition of SV40 replication in simian cells by specific pBR322 DNA sequences. Nature (London) 293:79-81.

26. Lusky, M., and M. Botchan. 1984. Characterization of the bovine papilloma virus plasmid maintenance sequences. Cell 36:391-401.

27. Mandel, M., and A. Higa. 1970. Calcium-dependent bacteriophage DNA infection. J. Mol. Biol. 53:159-162.

28. Maniatis, T., E. F. Fritsch, and J. Sambrook. 1982. Molecular cloning: a laboratory manual. Cold Spring Harbor Laboratory, Cold Spring Harbor, N.Y.

29. Maniatis, T., S. G. Kee, A. Efstratiadis, and F. C. Kafatos. 1976. Amplification and characterization of a $\beta$-globin gene synthesized in vitro. Cell 8:163-182.

30. McKnight, S. L., C. M. Croce, and R. Kingsbury. 1979. Introduction of isolated DNA sequences into cultured eukaryotic cells. Carnegie Inst. Wash. Year Book 78:56-61.

31. Mellon, P., V. Parker, Y. Gluzman, and T. Maniatis. 1981. Identification of DNA sequences required for transcription of the human $\alpha$ l-globin gene in a new SV40 host-vector system. Cell 27:279-288.

32. Meneguzzi, G., G. Barbanti-Brodano, and G. Milanesi. 1978. Transcription of BK virus DNA by Escherichia coli RNA polymerase: size and sequence analysis of RNA. J. Virol. 25:940-943.

33. Mulligan, R. C., and P. Berg. 1980. Expression of a bacterial gene in mammalian cells. Science 209:1422-1427.

34. Mulligan, R. C., B. H. Howard, and P. Berg. 1979. Synthesis of rabbit $\beta$-globin in cultured monkey kidney cells following infection with a SV40- $\beta$-globin recombinant genome. Nature (London) 277:108-114.

35. Norkin, L.C. 1982. Papovaviral persistent infections. Microbiol. Rev. 46:384-425.

36. Padgett, B. 1980. Human papovaviruses, p. 339-370. In J. Tooze (ed.), Molecular biology of tumor viruses. II. DNA tumor viruses. Cold Spring Harbor Laboratory, Cold Spring Harbor, N.Y.

37. Panicali, D., and E. Paoletti. 1982. Construction of poxviruses as cloning vectors: insertion of the thymidine kinase gene from herpes simplex virus into the DNA of infectious vaccinia virus. Proc. Natl. Acad. Sci. U.S.A. 79:4927-4931. 
38. Radloff, F., W. Bauer, and J. Vinograd. 1967. A dye-buoyantdensity method for the detection and isolation of closed circular duplex DNA: the closed circular DNA in HeLa cells. Proc. Natl. Acad. Sci. U.S.A. 57:1514-1521.

39. Rigby, P. W. J. 1982. Expression of cloned genes in eukaryotic cells using vector systems derived from viral replicons, p. 83141. In R. Williamson (ed.), Genetic engineering, vol. 3. Academic Press, Inc., New York.

40. Rigby, P. W. J. 1983. Cloning vectors derived from animal viruses. J. Gen. Virol. 64:255-266.

41. Rosenthal, N., M. Kress, P. Gruss, and G. Khoury. 1983. BK viral enhancer element and a human cellular homolog. Science 222:749-755.

42. Ryder, K., A. L. DeLucia, and P. Tegtmeyer. 1983. Binding of SV40 A protein to the BK virus origin of DNA replication. Virology 129:239-245.

43. Sarver, N., P. Gruss, M.-F. Law, G. Khoury, and P. M. Howley. 1981. Bovine papilloma virus deoxyribonucleic acid: a novel eucaryotic cloning vector. Mol. Cell. Biol. 1:486-496.

44. Scangos, G., and F. H. Ruddle. 1981. Mechanisms and applications of DNA-mediated gene transfer in mammalian cells: a review. Gene 14:1-10.

45. Seif, I., G. Khoury, and R. Dhar. 1979. The genome of human papovavirus BKV. Cell 18:963-977.

46. Shimotohno, K., and H. M. Temin. 1981. Formation of infectious progeny virus after insertion of herpes simplex thymidine kinase gene into DNA of an avian retrovirus. Cell 26:67-77.

47. Solnick, D. 1981. Construction of an adenovirus SV 40 recombinant producing SV40 T-antigen from an adenovirus late promoter. Cell 24:135-143.

48. Southern, E. 1975. Detection of specific sequences among DNA fragments separated by gel electrophoresis. J. Mol. Biol. 98:503-517.

49. Southern, P. J., and P. Berg. 1982. Transformation of mammalian cells to antibiotic resistance with a bacterial gene under control of the SV40 early region promoter. J. Mol. Appl. Genet.
$1: 327-341$

50. Spaete, R. R., and N. Frenkel. 1982. The herpes simplex virus amplicon: a new eukaryotic defective virus cloning amplifying vector. Cell 30:295-304.

51. Spandidos, D. A., P. R. Harrison, and J. Paul. 1982. Replication and amplification of recombinant plasmid molecules as extrachromosomal elements in transformed mammalian cells. Exp. Cell Res. 141:149-158.

52. Tegtmeyer, P., M. Schwartz, J. K. Collins, and K. Rundell. 1975. Regulation of tumor antigen synthesis by simian virus 40 gene A. J. Virol. 16:168-178.

53. Thummel, C., R. Tjian, and T. Grodzicker. 1981. Expression of SV40 T-antigen under control of adenovirus promoters. Cell 23:825-836

54. Tooze, J. (ed.). 1981. Molecular biology of tumor viruses, revised edition 2. Cold Spring Harbor Press, Cold Spring Harbor, N.Y.

55. Tsui, L.-C., M. L. Breitman, L. Siminovitch, and M. Buchwald. 1982. Persistence of freely replicating SV40 recombinant molecules carrying a selectable marker in permissive simian cells. Cell 30:499-508.

56. Vogelstein, B., and D. Gillespie. 1979. Preparative and analytical purification of DNA from agarose. Proc. Natl. Acad. Sci. U.S.A. 76:615-619.

57. Wei, C.-M., M. Gibson, P. G. Spear, and E. M. Scolnick. 1981 Construction and isolation of a transmissible retrovirus containing the src gene of Harvey murine sarcoma virus and the thymidine kinase gene of herpes simplex virus type 1 . J. Virol. 39:935-944.

58. Wigler, M., R. Sweet, G. K. Sim, B. Wold, A. Pellicer, E. Lacy, T. Maniatis, S. Silverstein, and R. Axel. 1979. Tranformation of mammalian cells with genes from prokaryotes and eukaryotes. Cell 16:777-785.

59. Yang, R. C. A., and R. Wu. 1979. BK virus DNA: complete nucleotide sequence of a human tumor virus. Science 206:456462. 